\title{
Cytokines as Key Players in the Pathophysiology of Preeclampsia
}

\author{
Raj Raghupathy \\ Department of Microbiology, Faculty of Medicine, Health Sciences Centre, Kuwait University, Safat, Kuwait
}

\section{Key Words}

Preeclampsia - Cytokines · Pregnancy · T helper 1 .

Thelper $2 \cdot$ Inflammation

\begin{abstract}
Preeclampsia (PE) is an important, common, and dangerous complication of pregnancy; it causes maternal and perinatal illness and is responsible for a high proportion of maternal and infant deaths. PE is associated with increased blood pressure and proteinuria, with a whole host of other potentially serious complications in the mother and fetus. The maternal syndrome in PE is primarily that of generalized dysfunction of the maternal endothelium, and this generalized endothelial dysfunction appears to be part of an exaggerated systemic inflammatory response that involves maternal leukocytes and proinflammatory cytokines. This review examines evidence that points to a significant role for the maternal immune system; inadequate trophoblast invasion of spiral arteries initiates ischemia and hypoxia in the placenta, resulting in an increased release of proinflammatory cytokines in the placenta. Placental ischemia and hypoxia also cause the enhanced release of trophoblast microparticles into the maternal circulation which stimulates increased induction of proinflammatory cytokines and the activation of maternal endothelial cells. This activation results in a systemic, diffuse endothelial cell dysfunction which is the funda-
\end{abstract}

\begin{tabular}{ll}
\hline KARGER & $\begin{array}{l}\text { ( } 2013 \text { S. Karger AG, Basel } \\
1011-7571 / 13 / 0227-0008 \$ 38.00 / 0\end{array}$ \\
E-Mail karger@karger.com & $\begin{array}{l}\text { This is an Open Access article licensed under the terms of the } \\
\text { www.karger.com/mpp }\end{array}$ \\
$\begin{array}{l}\text { Creative Commons Attribution-NonCommercial 3.0 Un- } \\
\text { ported license (CC BY-NC) (www.karger.com/OA-license), } \\
\text { applicable to the online version of the article only. Distribu- } \\
\text { tion permitted for non-commercial purposes only. }\end{array}$
\end{tabular}

mental pathophysiological feature of this syndrome. Recent evidence also supports important roles for proinflammatory cytokines in hypertension, proteinuria, and edema which are characteristic features of PE.

(c) 2013 S. Karger AG, Basel

\section{Introduction}

The process of pregnancy is besieged by many potential challenges, of which one of the most common is preeclampsia (PE), a multisystem disorder unique to pregnancy associated with elevated blood pressure (BP) and proteinuria typically presenting after 20 weeks of gestation. Gestational hypertension is the presence of new hypertension (usually systolic BP $>140 \mathrm{~mm} \mathrm{Hg}$ and/or diastolic BP $>90 \mathrm{~mm} \mathrm{Hg}$ ) occurring in the second half of pregnancy, while $\mathrm{PE}$ is the combination of gestational hypertension with new proteinuria [1].

Worldwide, PE is the most common of the various hypertensive disorders of pregnancy, affecting an estimated $2-10 \%$ of pregnant women $[2,3]$. More than 4 million women across the world develop this disorder every year [4], and an estimated 50,000-76,000 women and 500,000 infants die of this condition every year [3]. In fact, PE is a principal cause of fetal morbidity and mortality and causes $15-20 \%$ of maternal deaths worldwide [5]. 


\section{Fig. 1. Proposed stages of events in PE.}

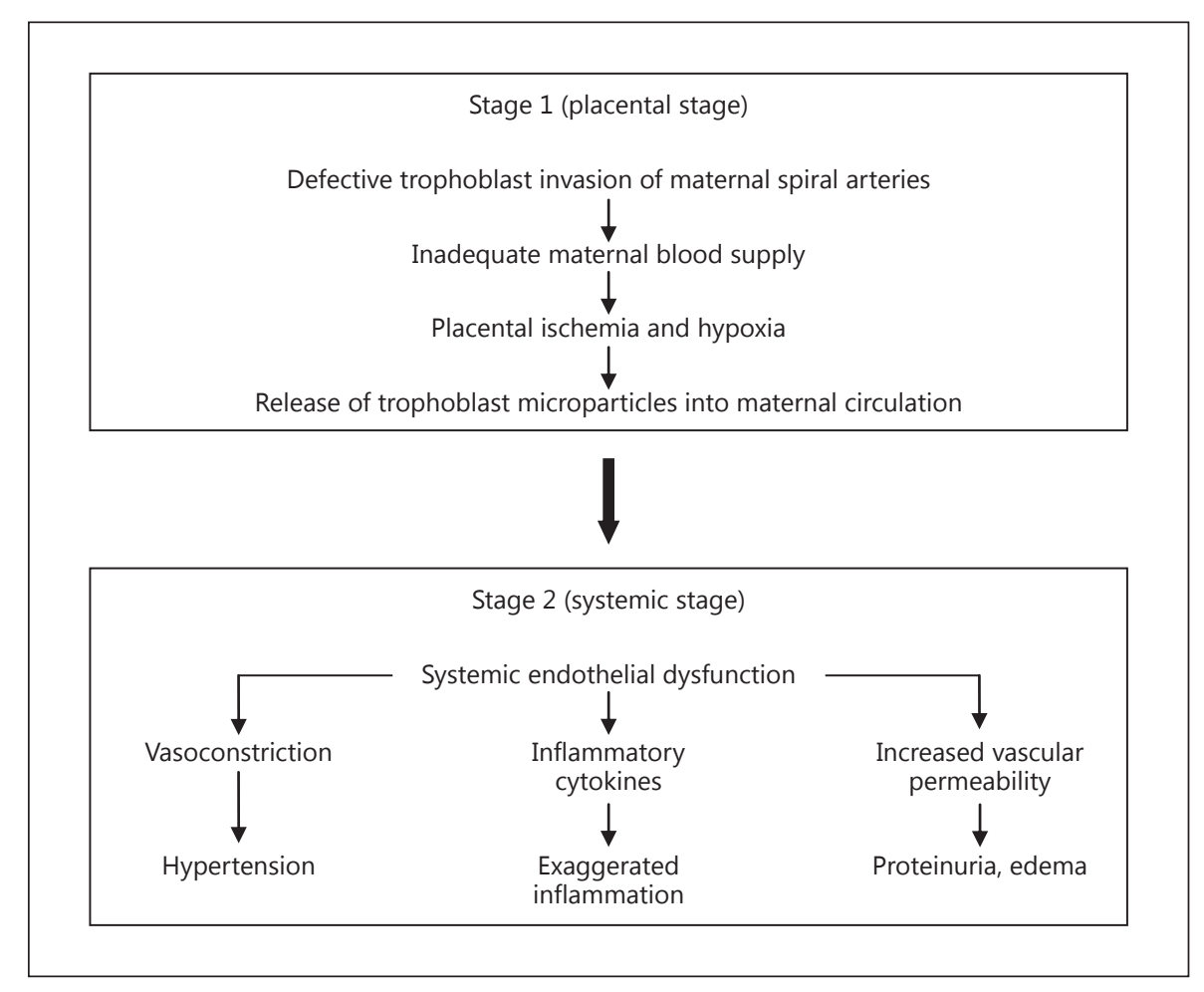

Symptoms of PE may include edema of the hands and face/eyes and weight gain; severe PE may present with headaches, abdominal pain, agitation, decreased urine output, nausea, vomiting, and vision changes. PE is perhaps the most dangerous complication of pregnancy because it has the greatest effect on maternal and infant outcomes $[3,6,7]$ and is the chief cause of protracted antenatal hospital stay, induced preterm delivery, and slow growth of infants. Adverse conditions associated with PE include maternal multisystem complications such as oliguria, thrombocytopenia, pulmonary edema, right upper quadrant pain, elevated liver enzymes, and unfavorable placental/fetal outcomes such as abruptio placentae, intrauterine growth restriction, oligohydramnios, and absent or reversed umbilical artery diastolic flow [7]. Thus, a wide range of potentially serious fetal and maternal conditions are associated with PE.

What induces PE? How is the pathophysiology of PE mediated? What are the mechanisms underlying PE-associated hypertension, proteinuria, and edema? These questions have plagued researchers and clinicians alike, even though PE has been known for a long time now. In 1916, Zweifel [8] described PE as 'a disease of theories' presumably because of the innumerable theories and speculations put forth to explain the etiopathogenesis of what has been described as 'a complex, elusive and unpredictable disease' $[9,10]$. Indeed, Saito [11] describes PE as involving a 'chaos of theories'. However, intensive research in the last decade has contributed to a better understanding of the pathogenesis of PE. Most investigators now agree that the basic cause of the diverse maternal symptoms of $\mathrm{PE}$ is a generalized dysfunction of maternal endothelium [12] which seems to be a part of a generalized systemic inflammatory response that involves maternal leukocytes.

\section{Pathogenesis of PE}

The sequence of events in PE is proposed to occur in two stages: a 'placental' stage (or stage 1) and a 'peripheral' stage (or stage 2) [12]. During stage 1, inadequate development of maternal spiral arteries results in a deficient maternal blood supply to the placenta, bringing about placental ischemia and hypoxia; this appears to be followed by stage 2 , consisting of the classic manifestations of widespread endothelial dysfunction, hypertension, proteinuria, and edema (fig. 1).

The fetus depends on the blood supply from the mother flowing into placental blood spaces via maternal spiral 
arteries which are the terminal branches of radial arteries that run from the uterus through the decidua. Spiral arteries, under normal circumstances, are invaded by placental cytotrophoblast cells which replace the endothelium of these arteries and remodel the vascular wall, causing the blood vessels to dilate [13] and thus better accommodate the increased blood supply needed by the fetus and placenta [14]. On the other hand, in PE, trophoblast invasion of spiral arteries is insufficient, resulting in narrower blood vessels [15] which are unable to transport adequate blood to the placenta which then becomes increasingly ischemic in the second half of the pregnancy [reviewed in 16]. Thus, shallow trophoblast invasion [17, $18]$ and improper remodeling of the spiral arteries [19, 20] are believed to result in abnormal prolongation of hypoxia. In addition to placental ischemia, acute atherosis of spiral arteries adds a further complication. Spiral arteries with poor trophoblast invasion and remodeling also show signs of acute atherosis which includes disruption of the endothelium, fibrinoid necrosis, and leukocytic infiltration, leading to partial or complete blockage of the arteries [21]. This secondary complication aggravates the problem of poor blood-conducting ability, resulting in hypoxia of the placenta which in turn causes several gross and histological changes such as infarcts, proliferation of the cytotrophoblast, and outgrowth lesions of the syncytiotrophoblast [22]. Perhaps the most relevant outcome of this damage to the placenta is the shedding of trophoblast cells and trophoblast microparticles into the maternal circulation which can be viewed as the beginning of stage 2 of PE [23].

Stage 2 of this disease was first described by Redman and colleagues [24] to be the result of diffuse maternal endothelial dysfunction manifested as endotheliosis of renal glomerulae, increased levels of components of the endothelial extracellular matrix, raised plasma levels of fibronectin and von Willebrand factor, increased vascular permeability, enhanced vascular resistance, and platelet aggregation. Furthermore, this generalized endothelial dysfunction can be attributed to trophoblast microparticles originating from the ischemic placenta [23, 24].

Microparticles are present in blood circulation even under normal physiological conditions and can induce cell signaling leading to processes like invasion, angiogenesis, and apoptosis; moreover, microparticles are also involved in thrombosis, inflammation, and vascular dysfunction [25]. Sargent et al. [24] demonstrated the presence of subcellular trophoblast microparticles [termed syncytiotrophoblast microparticles (STBM)] in the plas- ma of normal pregnant women; levels of STBM were shown to be significantly higher in PE $[24,26,27]$. This led to the hypothesis that STBM is shed into the circulation of PE patients in higher amounts than in normal pregnancies due to oxidative stress brought about by a poor blood supply and hypoxia [27]. STBM are made up of products of trophoblast apoptosis [28] and are reported to inhibit the proliferation of endothelial cells in culture and disrupt the continuity of established endothelial cell monolayers [29]. STBM preparations from PE placentas are qualitatively not different from STBM preparations from normal placentas; their ability to induce endothelial dysfunction is proposed to be due to higher levels in PE $[23,26,27]$. More interestingly, these microparticles provoke endothelial cells to release proinflammatory factors $[30,31]$ and induce maternal leukocytes and endothelial cells to produce proinflammatory cytokines [12, 32]; this has relevance for the induction of an inflammatory state, which is the focus of this review. In fact, the generalized an excessive maternal inflammatory reaction seen in PE appears to be associated with an increased release of these microparticles [32]. Also released from the placenta in PE are antiangiogenic factors that may act on the endothelia of organs such as the kidney, liver, and brain, resulting in the production, by damaged endothelial cells, of proinflammatory cytokines [reviewed in 16].

\section{PE: An Immune-Mediated Disease?}

The placenta has the rather challenging task of maintaining a very delicate balance between allowing trophoblast invasion of spiral arteries to take place on the one hand and preventing uncontrolled invasion on the other. Maternal immune cells appear to serve as immunological policemen, thwarting an overly robust trophoblast invasion; at the same time, an exaggerated immune response may restrain this to the extent that it results in insufficient invasion of the arteries and consequently poor vascular remodeling, constricted blood flow, and hypoxia. A role for the immune system has also been shown for the placental damage seen in PE; increased levels of some complement components [33] and higher levels of $\operatorname{IgG}$ are found in preeclamptic placentas compared to placentas from normotensive pregnancies [34].

A role for immunologic effectors is more evident in stage 2 of PE, leading up to widespread endothelial damage. Neutrophils are abnormally activated in PE [35] and this activation has been attributed to immune mechanisms, e.g. inflammatory cytokines produced by $\mathrm{T}$ cells.
Raghupathy 
Activated neutrophils could cause vascular damage and interact with platelets and coagulation systems. Clark et al. [35] suggest that the activation of neutrophils, and endothelial cells and platelet/coagulation activate one another, bringing about a vicious cycle of mutual activation. In addition to neutrophils, other immune effectors that appear to play critical roles are cytokines, which are perhaps the most important initiators and mediators of inflammation and endothelial dysfunction; thus, a great deal of attention has been focused on cytokines produced both by the placenta and by leukocytes in the periphery.

\section{Pregnancy, PE, and Inflammation}

Pregnancy has been described as a state of 'mild, controlled inflammation' [36], while PE appears to be a state of an exaggerated inflammatory response $[37,38]$. Both normal and preeclamptic pregnancies show an increased inflammatory response with increasing gestational age [39]. It is suggested that a mild inflammatory response in a normal, successful pregnancy is actually beneficial to pregnancy [40], and that when this inflammatory response becomes amplified it results in the development of PE. Inflammation is necessary during pregnancy, but at the same time needs to be tightly controlled to prevent excessive inflammation, and is probably achieved by reducing the production of proinflammatory cytokines and/or increasing the production of anti-inflammatory cytokines $[41,42]$. The abnormal inflammatory response seen in PE is believed to be caused by the higher levels of STBM shed into maternal blood [28-31, 43] which are suggested to cause endothelial dysfunction primarily via the induction of proinflammatory cytokines $[12,23,24$, $27,36]$. Many of the symptoms of PE can be attributed to an inappropriate or exaggerated activation of maternal inflammatory responses. In addition to the activation of neutrophils and monocytes, PE is associated with enhanced production of phospholipase A2, an important mediator of inflammatory reactions [44], increased expression of cell-surface markers of leukocyte activation, C-reactive protein [45], activin A [46], and several inflammatory cytokines. A recent large case-control study showed an association between PE and SEPS1, an inflammatory response gene which is proposed to be responsible for the elevated levels of proinflammatory cytokines and other mediators of inflammation observed in $\mathrm{PE}$ [47]. Austgulen et al. [48] showed that levels of the soluble adhesion molecules ICAM-1, VCAM-1, and E-selectin are increased in preeclamptic pregnancies, while levels of these markers and mediators of inflammation in normal pregnancies are significantly lower and similar to those in nonpregnant women.

Toll-like receptors (TLRs) also appear to contribute to the induction of PE [49]. TLRs are part of the innate immune system, and these cell surface receptors recognize evolutionarily conserved pattern-recognition molecular patterns on pathogens. Stimulation of TLRs on monocyte surfaces elicits the production of several cytokines. Interestingly, a recent study showed that the stimulation of TLR4 using low doses of lipopolysaccharide brings about a PE-like syndrome in pregnant rats [49]; indeed, the expression of TLR4 has been shown to be elevated in interstitial trophoblast cells of preeclamptic placentas [50].

\section{Cytokines and PE}

Substantial evidence has accrued over the years supporting roles for cytokines in the pathogenesis of $\mathrm{PE}$ at the early placental stage and in the later systemic stage as well. Cytokines play critical, essential roles in signaling between cells of the immune system, with a prolific range of regulatory activities including the recruitment, activation, stimulation, killing, and suppression of immune and nonimmune cells. Interestingly, research in the last two decades has shown that cytokines are also involved in several events in pregnancy such as ovulation, implantation, placentation, and parturition [51]. Cytokines like granulocyte-macrophage colony-stimulating factor (GM-CSF), colony-stimulating factor-1, IL-3 [52], and IL-10 [53] contribute to the success of pregnancy, while cytokines such as TNF- $\alpha$ and IFN- $\gamma$ have been shown to have harmful effects on pregnancy $[54,55]$. IL-2, TNF- $\alpha$, and IFN- $\gamma$ are characteristic of T helper 1 (Th1)-type immunity and induce several cell-mediated cytotoxic and inflammatory reactions. Th2-type cells, on the other hand, secrete the Th2 cytokines IL-4, IL-5, IL-6, and IL-10 and are associated with help for humoral immunity [56, 57]. Th2-type immunity is associated with a normal pregnancy, whereas a strong Th1 reactivity is associated with pregnancy complications such as recurrent spontaneous miscarriage $[58,59]$, preterm delivery $[60,61]$, and premature rupture of fetal membranes [62]. In addition to being classified as Th1 and Th2 cytokines, cytokines can also be classified as pro- and anti-inflammatory. Cytokines such as IL-1, IL-2, IL-8, TNF- $\alpha$, and IFN- $\gamma$ are proinflammatory, and increased levels of such proinflammatory cytokines are associated with pregnancy complications such as preterm delivery [63] and intrauterine growth retardation [64]. 


\section{Cytokines in the Placenta}

Cytokines are produced by cells of normal placentas and by leukocytes infiltrating the placenta, and receptors for cytokines are also expressed in the placenta; thus, both sources and targets of cytokines are present in the placenta $[51,65,66]$. Proinflammatory cytokines are produced by placental trophoblasts and also by macrophages and stromal cells of the placenta [67-69]. The anti-inflammatory cytokines IL- 4 and IL-10 are also secreted by placental tissues [70]. Cytokines have been shown to play beneficial roles in several normal physiologic processes in the placenta; these include trophoblast invasion and differentiation and placental proliferation and angiogenesis $[51,71,72]$.

Widespread upregulation of cytokines in preeclamptic placentas, including proinflammatory cytokines like TNF- $\alpha$ and their receptors, have been shown in DNA microarray studies [73]. The expression and secretion of TNF- $\alpha$ [74-76] and IL-1 [77-79] are elevated in the placentas of preeclamptic women. Hypoxia-reoxygenation due to intermittent perfusion of the placenta has been shown to induce the production of TNF- $\alpha$ and IL-1 [75, $80-82]$; Benyo and colleagues $[83,84]$ demonstrated increased production of the proinflammatory cytokines TNF- $\alpha$ and IL- 1 by the normal human placenta under conditions of low oxygen tension. Considering that placental hypoxia occurs in PE, this could well explain the elevated production of these two cytokines. High local production of TNF- $\alpha$ may have significant effects, including increased trophoblastic apoptosis resulting in enhanced syncytial shedding and impaired placental function [85].

Elevated levels of other proinflammatory cytokines, i.e. IL-2 [78] and IL-18 [86], have also been shown in preeclamptic placentas. IL-18 is a proinflammatory cytokine which, in the presence of IL-12, tips the balance of immune reactivity towards a Th1 phenotype. High levels of IL-18 along with high levels of IL-12 [87] in PE are proposed to cause Th1 dominance [88]. Lockwood et al. [89] demonstrated higher levels of IL-6 mRNA and protein in leukocyte-free decidual cells from subjects with PE. Human endometrial endothelial cells have been recently shown to be capable of phagocytosing apoptotic trophoblasts and then secreting the proinflammatory cytokine IL-6 [90]; this might be one of the mechanisms that contribute to the inflammatory response seen in preeclamptic placentas. Increased production of IFN- $\gamma$, a Th1 proinflammatory cytokine, has been found in decidual lymphocytes [91] and choriodecidual cells of placentas [92] from preeclamptic pregnancies.
While PE is associated with increased levels of proinflammatory cytokines, it is also associated with decreased placental production of the anti-inflammatory cytokine IL-10 [93-95]. Considering that IL-10 is a strong suppressor of proinflammatory cytokines such as IFN- $\gamma$ and TNF- $\alpha$, it is suggested that the placenta responds to hypoxia in PE with insufficient IL-10 production, leading to increased or uncontrolled production of pro-inflammatory cytokines [66]. Furthermore, IL-10 has anti-apoptotic and anti-inflammatory capabilities, and it is therefore quite likely that the decreased IL-10 in the placenta is at least partly responsible for the increased apoptosis of the trophoblast seen in PE [96-98]. While apoptosis is actually necessary for normal placentation, excessive apoptosis or inadequate clearance of apoptotic debris may lead to increased production of proinflammatory cytokines by macrophages [99]. In addition to proinflammatory cytokines, decidua from a murine model of PE display higher levels of GM-CSF as well as increased numbers of both macrophages and dendritic cells when compared to control animals [100]. Furthermore, TNF- $\alpha$ and IL-1 induce increased production of GM-CSF by cultured decidual cells, leading to the suggestion of important roles for GM-CSF in inducing the activation of macrophages and dendritic cells in PE.

\section{Cytokines in the Periphery}

Levels of proinflammatory cytokines are increased in the blood and in blood leukocytes in PE. Elevated concentrations of TNF- $\alpha$ have been observed in the blood of women with PE [101-105]. The placenta may not be the major contributor to the high TNF- $\alpha$ levels seen in peripheral blood [84], and in fact peripheral leukocytes, which are in any case in an activated state in PE [106] may contribute significantly to the TNF- $\alpha$ levels in peripheral blood [107]. Levels of soluble TNF- $\alpha$ receptor, a more reliable marker for TNF activity, are also increased in PE as compared to normal pregnancies [108]. Support for a cause-and-effect association between TNF- $\alpha$ and PE comes from Sibai et al. [109] who showed that serum levels of TNF-R2 receptor are indeed elevated prior to overt $\mathrm{PE}$, suggesting a pathogenetic role for these proinflammatory cytokines.

Similarly, enhanced plasma levels of IL-1 [77], IL-2 [110], IL-6 [83, 101, 111, 112], IL-8, and IL-18 [86] have been reported in preeclamptic women. Elevations of IL-6 and IL- 8 have also been shown in the amniotic fluid of preeclamptic patients [113]; in fact, elevated levels of IL-6 have been shown to be associated with the onset of PE.
Raghupathy 
A recent study using a multiplex suspension array technique compared levels of cytokines, chemokines, and adhesion molecules in normotensive pregnancies versus preeclamptic pregnancies [114]. Serum from women with PE had increased Th1/Th2 cytokine ratios as well as increased levels of the cytokines IL- 6 and TNF- $\alpha$, the chemokines IL-8, IP-10, and MCP-1, and the adhesion molecules ICAM-1 and VCAM-1, supporting the existence of a systemic proinflammatory condition in $\mathrm{PE}$.

In contrast to the generally increased levels of proinflammatory cytokines, the blood levels of some anti-inflammatory cytokines such as IL-4 $[92,115]$ and IL-10 [95] are reduced in patients with PE.

The production of cytokines by peripheral blood mononuclear cells (PBMC) has been investigated in several studies. Maternal PBMC produce higher levels of the proinflammatory cytokines TNF- $\alpha$ [116], IFN- $\gamma$ [116118], IL-2 [104, 119], IL-1 [120], IL-6 [120], and IL-8 $[105,111,120]$. On the other hand, reduced production of IL-10 [111, 117, 118, 121] and IL-5 by PBMC from patients with PE [111] has been reported.

We conducted a study designed to ascertain whether a Th1-biased cytokine profile exists in women with PE as compared to normal pregnant women. We found that significantly higher levels of the proinflammatory cytokines IFN- $\gamma$ and TNF- $\alpha$ were produced by women with $\mathrm{PE}$ versus normal pregnant women, who on the contrary showed significantly greater production of the Th2 cytokines IL-4, IL-5, and IL-10. A comparison of the ratios of Th2 to Th1 cytokines indicated significantly higher Th1/ proinflammatory cytokine production in $\mathrm{PE}$ as compared to normal pregnancies [122]. Flow cytometric measurement of intracellular cytokines demonstrated a shift towards predominantly Th1-type reactivity in PE [119]. The increased levels of activated T cells [123] and the tilt towards Th1 dominance in PE suggests important roles for T cells in the pathogenesis of PE. There appears to be a clear increase in Th1 versus Th2 reactivity in women with PE $[42,124]$, and this has been shown to be initiated before the clinical manifestation of PE, suggesting a causeand-effect relationship [109].

Zenclussen [125] described a mouse model of PE in which the adoptive transfer of Th1-like cells into pregnant mice provokes PE symptoms such as increased BP and glomerulonephritis accompanied by proteinuria, in addition to effecting an inflammatory profile among uterine immune cells. This study provides strong support for a role for Th1-type reactivity in PE [125].

What stimulates the production of proinflammatory cytokines in PE? Trophoblast microparticles may con- tribute to this in great part as these have been shown to stimulate the production of the proinflammatory cytokines TNF- $\alpha$, IL-12, IL-18, IL-1 $\beta$, IL- 6 , and IL- 8 by monocytes [126] in PE. Cytokines may contribute to an increased release of trophoblast microparticles by stimulating enhanced trophoblast apoptosis, and subsequently these microparticles could cause elevated systemic production of proinflammatory cytokines, thus supporting the contention that cytokines play key roles in both stages of PE. In addition to Th1 and Th2 cells, T cells may also differentiate into the distinct lineages of Treg and Th17 cells. Treg cells play key roles in the regulation of inflammation, while Th17 cells secrete the proinflammatory cytokine IL-17 and mediate potent tissue inflammation. The numbers of a subset of regulatory $\mathrm{T}$ cells with immunosuppressive capabilities, i.e. Treg cells, are significantly lower in PE compared to normal pregnancies [127], while Th17 cells are increased [11]. The increase in proinflammatory Th17 cells and the decrease in the immunosuppressive Treg cells is proposed to contribute to the pathophysiology of PE [128] via the induction of unbridled inflammation and endothelial dysfunction [11]. However, the laboratory of Zenclussen demonstrated that the levels of Treg cells were similar in PE and normal pregnancy, questioning the role of Treg cells in averting PE [129].

\section{Mechanisms of Action of Cytokines in PE}

The pathophysiologic mechanisms underlying the initial placental changes and subsequent development of endothelial dysfunction, hypertension, proteinuria, and edema in PE have been the subject of intense investigation over the years, and these aspects are now much better understood. PE is basically a condition of generalized endothelial cell dysfunction [12, 23]; the disturbed endothelium results in the well-known classical features of PE the hypertension is attributable to vasoconstriction, the proteinuria is attributable to glomerular endotheliosis, and the edema is attributable to increased vascular permeability [47].

Generalized activation or injury of maternal vascular endothelial cells leading to microthrombus formation and vasospasm [130] is an important observation in PE. Given the powerful effects of cytokines on endothelial cells (table 1), the increased tendency for maternal blood cells to produce inflammatory cytokines in PE is significant. Maternal proinflammatory cytokines are likely to be the most important effectors of these effects $[42,100,101$, 
Table 1. Inflammatory cytokines and endothelial dysfunction

\begin{tabular}{ll}
\hline TNF- & $\begin{array}{l}\text { Activates endothelial cells } \\
\text { Increases coagulation }\end{array}$ \\
& $\begin{array}{l}\text { Increases the expression of adhesion molecules } \\
\text { Increases vascular permeability }\end{array}$ \\
& Induces microvascular leakage \\
\hline IL-1 & $\begin{array}{l}\text { Increases thrombin production and coagulation } \\
\text { Induces the production of platelet-activating factor } \\
\text { Stimulates the expression of adhesion molecules }\end{array}$ \\
\hline IL-6 & Increases vascular permeability \\
\hline IL-8 & Activates endothelial cells \\
\hline
\end{tabular}

$107,109,113,122]$. In fact, Redman et al. [131] affirmed that the clinical features of PE are best described as an excessive maternal inflammatory response mediated by cytokines, and that cytokine action is one of the most attractive hypotheses of immunological dysfunction in this syndrome.

At the level of the placenta, the cytokines IL- 6 and TNF- $\alpha$ were shown to induce excessive or abnormal apoptotic and necrotic death of trophoblast cells; these cells were shown to induce endothelial activation when shed [132]. Thus cytokines appear to be involved in the early (i.e. stage 1) events of PE. The pattern of increased placental and systemic cytokines appears to be consistent with increased systemic inflammatory activation, the release of vasoconstrictory factors, endothelial dysfunction, and hypertension, which are all part of the syndrome of PE [133]. The widespread maternal vascular endothelial dysfunction is suggested to be caused by proinflammatory cytokines [66] and, along with other mediators such as endothelin and thromboxane, are proposed to contribute to hypertension, proteinuria, and edema [130]. Benyo et al. [83] pointed out that proinflammatory cytokines are 'notorious' for effecting changes in the endothelium in the same manner as that seen in PE. TNF- $\alpha$ has potent effects on endothelial and platelet function, it enhances coagulation, microvascular leakage, activation of vasoconstrictive endothelial cells, and production of antiangiogenesis factors like tissue factor $[134,135]$. TNF- $\alpha$ and IL-1 cause increased production of thrombin, platelet-activating factor, and vascular cell adhesion molecule-1, increased endothelial cell permeability [136], and enhanced coagulation, and thus instigate inflammatory responses [137-139]. TNF- $\alpha$ has been shown to induce the activation of endothelial cells and to cause endothelial damage [75]. Increased concentrations of IL-8 are associated with increased activation of neutrophils [140], while IL-6 is known to activate endothelial cells [89], to induce increased permeability of endothelial cells, and to bring about systemic effects that resemble the inflammatory acute phase response.

It may be pertinent to refer to another factor that appears to be involved in the pathogenesis of PE. Zenclussen et al. [141] showed that the expression of the heme-degrading enzymes heme oxygenases (HO)-1 and HO-2 is reduced in PE. They suggested that low expression of HO-2 may lead to enhanced levels of free heme at the feto-maternal interface, followed by upregulation of adhesion molecules which would then encourage the migration of inflammatory cells to the feto-maternal interface; this points to the involvement of HO in PE [142]. HO-1 plays an important role in placental vasculature development, and a deficiency in HO-1 may contribute to pregnancy complications, such as PE. The unique combination of tissue-protective, smooth-muscle-relaxing, and angiogenesis-regulatory properties makes $\mathrm{HO}-1$ a key player in the maintenance of a healthy pregnancy through a direct effect on placental structural and vascular development [143].

A fascinating nexus between cytokines and BP control is now being unraveled. Hayashi et al. [144] reported a positive correlation between increased production of the inflammatory cytokines IL- 2 , IFN- $\gamma$, and TNF- $\alpha$ by peripheral blood leukocytes in PE and mean BP. Chronic infusions of IL- 6 or TNF- $\alpha$ into normal pregnant rats increase arterial pressure and affect renal hemodynamics [41]. A recent study on pregnant baboons showed that the infusion of TNF- $\alpha$ is followed by an increase in systolic and diastolic BP and proteinuria, indicating that TNF- $\alpha$ can induce the clinical and biochemical features of human PE and also showing a clear association of TNF- $\alpha$ with endothelial dysfunction and BP control [145]. TNF- $\alpha$ activates the endothelin system in placental, vascular, and renal tissues, while IL- 6 activates the reninangiotensin system [41]. Proinflammatory cytokines produced in PE may contribute to hypertension by inducing the production of vascular mediators that result in vasoconstriction and consequently hypertension [146]. Cytokines are suggested to be linked to hypertension by provoking inflammation, which would result in vascular injury and may also contribute to elevated BP by causing kidney injury [147]. In a rat model of PE, Tinsley et al. [148] showed that the Th1-like cytokines IL-2, IL-12, and IFN- $\gamma$ were elevated; immunosuppression with azathioprine or mycophenolate not only resulted in a significant reduction of Th 1 cytokines but also decreased the associ-
Raghupathy 
ated hypertension, proteinuria, and endothelial dysfunction (table 2).

Increased Th1 reactivity $[42,122]$ and Th17 levels [149] in PE may induce exaggerated systemic inflammation and vascular endothelial dysfunction. That TNF- $\alpha$ may contribute directly to proteinuria is supported by a recent study on diabetic nephropathy in which a positive correlation was observed between plasma TNF- $\alpha$ levels and urinary protein concentrations [150].

\section{Immunomodulation for Therapeutic Intervention in PE?}

The possibility of rational development of immunomodulatory approaches for the treatment of PE is supported by research on anti-inflammatory cytokines like IL-10 and on the suppression of proinflammatory cytokines.

A negative correlation has been reported between BP and serum levels of IL-10 [94], and this has also been demonstrated experimentally in nonhuman primates [151]. A recent elegant study by Chatterjee et al. [152] showed that TLR3 activation during murine pregnancy induced an increase in systolic BP and endothelial function, demonstrating a connection between immune activation and symptoms of PE. TLR3 activation was shown to be associated with a proinflammatory state along with an increase in proinflammatory cytokines. Interestingly, a deficiency in IL-10 along with TLR3 activation brings about an exacerbation of PE symptoms; the addition of recombinant IL-10 prevented these symptoms, demonstrating the importance of IL-10 in this equation. These observations are significant given the well-documented anti-inflammatory properties of IL-10 and the demonstration that IL-10 deficiency is associated with PE-like symptoms. In pregnant baboons, the administration of anti-IL-10 antibody results in a significant increase in mean arterial pressure via regulation of vasodilation [151]. Chatterjee et al. [152] proposed that recombinant IL-10 may be considered for use in preventing PE. More evidence of the important role of IL-10 comes from observations that IL-10 knockout mice have mild hypertension, endothelial dysfunction, and inflammation [153].

The possibility of manipulating cytokine production for therapeutic intervention in PE is supported by the recent study of Keiser et al. [154]. This study on pregnant rats showed that progesterone inhibits TNF- $\alpha$-stimulated production of endothelin-1 by endothelial cells and suggested that such immunomodulatory approaches may be
Table 2. Cytokines and hypertension

Infusion of TNF- $\alpha$ or IL- 6 into pregnant rats increases arterial BP.

Infusion of TNF- $\alpha$ into pregnant baboons causes increases in BP and proteinuria.

TNF- $\alpha$ activates the endothelin system in the kidneys.

IL- 6 activates the renin-angiotensin system.

Proinflammatory cytokines cause vasoconstriction.

Suppression of proinflammatory cytokines results in reduction of hypertension and proteinuria.

There is a negative correlation between IL-10 levels and BP.

Infusion of IL-10 leads to improvement of PE-like symptoms in mice.

considered for PE. This study and the experiments on infusion of IL-10 offer a scope for optimism that better understanding of the pathogenesis of this rather mysterious disorder will lead to the rational development of treatments. Our work demonstrating the effects of the orally administered progesterone derivative dydrogesterone (6-dehydro-9 $\beta$, 10a-progesterone) is pertinent. Dydrogesterone (Duphaston ${ }^{\circledR}$ ) is a potent orally administered progestogen, similar to endogenous progesterone in its molecular structure and pharmacological effects, with a high affinity for the progesterone receptor. We have shown that dydrogesterone brings about a significantly reduced secretion of the Th1 cytokines IFN- $\gamma$ and TNF- $\alpha$ and a significant increase in the levels of the Th2 cytokines IL-4 and IL- $6[155,156]$. In view of the fact that the relative levels of Th1 and Th2 cytokines are probably of greater importance than their absolute levels alone, we calculated the ratios of Th 1 to Th 2 cytokines and found a marked reduction in the Th1/Th2 ratios (e.g. IFN- $\gamma / \mathrm{IL}-4$, IFN- $\gamma /$ IL-10) in PBMC cultures containing dydrogesterone. Thus, dydrogesterone redirects Th1/Th2 profiles in lymphocytes from women with recurrent miscarriage [155] and preterm delivery [156] by downregulating the production of proinflammatory cytokines and upregulating the production of anti-inflammatory cytokines [157]. This could well result in a substantial swing in Th1/Th2 reactivity towards the pregnancy-conducive Th2 profile and away from the potentially harmful Th1 profile. In fact, dydrogesterone downregulates the very cytokines, i.e. TNF- $\alpha$ and IFN- $\gamma$, that are implicated in many of the manifestations of PE. Redman et al. [131] suggested that the clinical features of PE are best described as an exces- 
sive maternal inflammatory response, mediated by cytokines. If indeed a Th1 predominance is responsible for $\mathrm{PE}$ and if Th2 bias is associated with a successful pregnancy, then immunomodulatory agents like dydrogesterone may be worth considering for use in PE. It is tempting to speculate that modulation of cytokine profiles by therapeutic supplementation with progestogens like dydrogesterone may be an attractive treatment option for PE.

\section{Conclusion}

Sufficient evidence from animal and human studies has now been gathered to reveal the pathogenesis of $\mathrm{PE}$ on the basis of the influence of cytokines both in the placenta and in the periphery. A unifying hypothesis for PE is that inadequate trophoblast invasion and remodeling of spiral arteries stimulate placental ischemia and hypoxia via intermittent perfusion of the placenta; this results in an increased release of trophoblast microparticles into the maternal circulation followed by increased production of maternal proinflammatory cytokines and activation of maternal endothelial cells. This is proposed to eventually lead to 'systemic, diffuse endothelial cell dysfunction', the fundamental pathophysiological feature of this syndrome.

While understanding the etiology and pathophysiology of PE is certainly of interest from a basic medical science perspective, it also has important implications for the treatment and management of this dangerous complication. There is renewed optimism that basic and clinical research which has helped elucidate the pathogenesis of this disease will lead to the rational design of interventions for the management and treatment of this important and common complication of pregnancy.

\section{Acknowledgements}

This work was supported by Kuwait University Research Administration grant MI 02/10.

\section{Disclosure Statement}

The author declares no conflict of interest.

\section{References}

1 Sibai BM: Hypertensive Disorders in Women. Philadelphia, Saunders, 2004.

-2 American College of Obstetricians and Gynecologists: Diagnosis and management of preeclampsia and eclampsia - ACOG practice bulletin No 22. Obstet Gynecol 2002;99:159167.

3 National Heart Lung and Blood Institute: Report of the Working Group on Research on Hypertension during Pregnancy. 2000. http:// www.nhlbi.nih.gov/health/prof/heart/hbp/ hbp_preg.htm (accessed June 10, 2010).

4 Barron WM: Hypertension; in Barron WM, Lindheimer MD (eds): Medical Disorders during Pregnancy. St. Louis, Mosby Year Book, 1991, pp 1-41.

5 Chang J, Elam-Evans LD, Berg CJ: Pregnancy-related mortality surveillance: United States 1991-1998. MMWR Surveill Summ 2003; $52: 1-8$.

6 Leeman L, Fontaine P: Hypertensive disorders of pregnancy. Am Fam Physician 2008; 78:93-100.

7 Redman CW, Walker I: Preeclampsia: The Facts - The Hidden Threat to Pregnancy. Oxford, Oxford University Press, 1992.

8 Zweifel P: Eklampsie; in Döderlein A (ed): Handbuch der Geburtshilfe. Wiesbaden, Bergmann, 1916, pp 672-723.
9 Maharaj B, Moodley J: Management of hypertension in pregnancy. Contin Med Educ 1994; 12:1581-1589.

10 Lain KY, Roberts JM: Contemporary concepts of the pathogenesis and management of preeclampsia. J Am Med Assoc 2002;287: 3183-3186.

11 Saito S: Th17 cells and regulatory T cells: new light on pathophysiology of preeclampsia. Immunol Cell Biol 2010;88:615-617.

12 Sargent IL, Borzychowski AM, Redman CW: Immunoregulation in normal pregnancy and pre-eclampsia: an overview. Reprod Biomed Online 2006;13:680-686.

13 Pijnenborg R, Robertson WB, Brosens I, et al: Trophoblast invasion and the establishment of haemochorial placentation in man and laboratory animals. Placenta 1981;2:71-91.

14 Robertson WB, Brosens I, Pijnenborg R, et al: The making of the placental bed. Eur J Obstet Gynecol Reprod Biol 1984;18:255-266.

15 Gerretsen G, Huisjes HJ, Hardonk MJ, et al: Trophoblast alterations in the placental bed in relation to physiological changes in spiral arteries. Br J Obstet Gynaecol 1983;90:34-39.

16 Eastabrook G, Brown M, Sargent I: The origin and end-organ consequence of pre-eclampsia. Best Pract Res Clin Obstet Gynecol 2011; 25:435-447.
17 Genbacev O, Joslin R, Damsky CH, et al: Hypoxia alters early gestation human cytotrophoblast differentiation/invasion in vitro and models the placental defects that occur in preeclampsia. J Clin Invest 1996;97:540-550.

18 Zhou Y, Genbacev O, Damsky CH, et al: Oxygen regulates human cytotrophoblast differentiation and invasion: implications for the endovascular invasion in normal pregnancy and in pre-eclampsia. J Reprod Immunol 1998;39:197-213.

19 Kingdom JC, Kaufmann P: Oxygen and placental vascular development. Adv Exp Med 1999;474:259-275.

20 Roberts JM, Gamill HS: Preeclampsia: recent insights. Hypertension 2005;46:1243-1249.

21 De Wolf F, Robertson WB, Brosens I: The ultrastructure of acute atherosis in hypertensive pregnancy. Am J Obstet Gynecol 1975;123: 164-174.

22 Kovo M, Schreiber L, Ben-Haroush A, et al: Placental vascular lesion differences in pregnancy-induced hypertension and normotensive fetal growth restriction. Am J Obstet Gynecol 2010;202:561e1-561e5.

23 Redman CW, Sargent IL: Latest advances in understanding preeclampsia. Science 2005; 308:1592-1594. 
24 Sargent IL, Germain SJ, Sacks GP, et al: Trophoblast deportation and the maternal inflammatory response in pre-eclampsia. J Reprod Immunol 2003;59:153-160.

25 Aharon A, Brenner B: Microparticles and pregnancy complications. Thrombosis Res 2011;3:567-571.

26 Goswami D, Tannetta DA, Magee LA, et al: Syncytiotrophoblast microparticle shedding is a feature of early onset pre-eclampsia but not normotensive intrauterine growth restriction. Placenta 2006;27:56-61.

27 Redman CW, Sargent IL: Circulating microparticles in normal pregnancy and pre-eclampsia. Placenta 2008;29:S73-S77.

28 Kumar S, Lo DY, Smarason AK: Pre-eclampsia is associated with increased levels of circulating apoptotic microparticles and fetal cellfree DNA. J Soc Gynecol Invest 2000;7:S181a.

-29 Cockell AP, Learmont JG, Smarason AK, et al: Human placental syncytiotrophoblast microvillous membranes impair maternal vascular endothelial function. Br J Obstet Gynecol 1997; 104:235-240.

-30 von Dadelszen P, Hurst G, Redman CW: Supernatants from co-cultured endothelial cells and syncytiotrophoblast microvillous membranes activate peripheral blood leukocytes in vitro. Hum Reprod 1999;14:919-924.

-31 Sargent IL, Johansen M, Chua S, et al: Clinical experience: isolating trophoblast from maternal blood. Ann NY Acad Sci 1994;731:154161.

32 Messarli M, May K, Hansson SR, et al: Fetomaternal interactions in pregnancies: placental microparticles activate peripheral blood monocytes. Placenta 2010;31:106-112.

- 33 Haeger M, Unander M, Norder-Hansson B, et al: Complement, neutrophil, and macrophage activation in women with severe preeclampsia and the syndrome of hemolysis, elevated liver enzymes, and low platelet count. Obstet Gynecol 1992;79:19-26.

34 Kitzmiller JL: Immunologic approaches to the study of preeclampsia. Clin Obstet Gynecol 1997;20:717-735.

-35 Clark P, Boswell F, Greer IA: The neutrophil and preeclampsia. Semin Reprod Endocrinol 1998;16:57-64.

-36 Borzychowski AM, Sargent IL, Redman CW: Inflammation and pre-eclampsia. Semin Fetal Neonatal Med 2006;11:309-316.

37 Sibai BM: Preeclampsia: an inflammatory syndrome? Am J Obstet Gynecol 2004; 191:1061-1066

38 Saito S, Shiozaki A, Nakashima A, et al: The role of the immune system in preeclampsia. Mol Aspects Med 2007;28:192-209.

-39 Brewster JA, Orsi NM, Gopichandran N, et al: Gestational effects on host inflammatory response in normal and pre-eclamptic pregnancies. Eur J Obstet Gyneco Reprod Biol 2008; 140:21-26.

40 Redman CW, Sargent IL: Preeclampsia and the systemic inflammatory response. Semin Nephrol 2004;24:565-570.
41 Lamarca BD, Ryan MJ, Gilbert JS, et al: Inflammatory cytokines in the pathophysiology of hypertension during pre-eclampsia. Curr Hypertens Rep 2007;9:480-485.

42 Saito S, Sakai M: Th1/Th2 balance in preeclampsia. J Reprod Immunol 2003;59:161173.

43 Knight M, Redman CWG, Linton EA, et al: Shedding of syncytiotrophoblast microvilli into the maternal circulation in pre-eclamptic pregnancies. Br J Obstet Gynecol 1998;105: 632-640.

44 Lim KH, Rice GE, de Groot CJ, et al: Plasma type II phospholipase A2 levels are elevated in severe preeclampsia. Am J Obstet Gynecol 1995;172:998-1002.

45 Germain SJ, Sargent IL, Redman CW: C-reactive protein and the maternal inflammatory response in normal pregnancy and pre-eclampsia. Hypertens Preg 2000;21:S150.

46 Muttukrishna S, North RA, Morris J: Serum inhibin and activin A are elevated prior to the onset of pre-eclampsia. Hum Reprod 2000;15: 1640-1645.

47 Moses EK, Johnson MP, Tammerdal L, et al: Genetic association of preeclampsia to the inflammatory response gene SEPS1. Am J Obstet Gynecol 2008;198:336.e1-336.e5.

48 Austgulen R, Lien E, Vince G, et al: Increased maternal plasma levels of soluble adhesion molecules ICAM-1, VCAM-1, E-selectin in preeclampsia. Eur J Obstet Gynecol Reprod Biol 1997;71:53-58.

49 Muttukrishna S, North RA, Morris J: Serum inhibin and activin A are elevated prior to the onset of pre-eclampsia. Hum Rerprod 2000; 15:1640-1645.

50 Kim YM, Romero R, Oh SY: Toll-like receptor 4: a potential link between 'danger signals' the innate immune system, and preeclampsia? Am J Obstet Gynecol 2005;193:921-927.

51 Bowen JM, Chamley L, Mitchell MD, et al: Cytokines of the placenta and extra-placental membranes: biosynthesis, secretion and roles in establishment of pregnancy in women. Placenta 2002;23:239-256.

52 Wegmann TG, Lin H, Guilbert L, et al: Bidirectional cytokine interactions in the maternal-fetal relationship: is successful pregnancy a Th2 phenomenon? Immunol Today 1993; 14:353-356.

53 Chaouat G, Meliani AA, Martal J, et al: IL-10 prevents naturally occurring fetal loss in the $\mathrm{CBAxDBA} / 2$ mating combination, and local defect in IL-10 production in this abortionprone combination is corrected by in vivo in jection of IFN- $\gamma$. J Immunol 1995; 154:42614268.

54 Chaouat G, Menu E, Clark DA, et al: Control of fetal survival in CBA $x$ DBA/2 mice by lymphokine therapy. J Reprod Fertil 1990;89: 447-458.

55 Yui J, Garcia-Lloret M, Wegmann TG, et al: Cytotoxicity of tumor necrosis factor- $\alpha$ $(\mathrm{TNF} \alpha)$ and gamma-interferon (IFN- $\gamma$ ) against primary human placental trophoblasts. Placenta 1994;15:819-828.
56 Romagnani S: T-cell subsets (Th1 versus Th2). Ann Allergy Asthma Immunol 2000;85: 9-18.

57 Mosmann TR, Sad S: The expanding universe of T-cell subsets. Immunol Today 1996;17: 138-146.

58 Hill JA, Anderson DJ, Polgar K: T helper 1-type cellular immunity to trophoblast in women with recurrent spontaneous abortion. J Am Med Assoc 1995;273:1933-1936.

59 Raghupathy R, Makhseed M, Azizieh F, et al: Cytokine production by maternal lymphocytes during normal human pregnancy and in unexplained recurrent spontaneous abortion. Hum Reprod 2000;15:713-718.

-60 Sykes L, MacIntyre DA, Yap XJ, et al: Th1:Th2 dichotomy of pregnancy and preterm labour. Mediators Inflamm 2012;2012:967629.

-61 Makhseed M, Raghupathy R, El-Shazly S, et al: Proinflammatory maternal cytokine profile in preterm delivery. Am J Reprod Immunol 2002;49:1-12.

62 Raghupathy R, Makhseed M, El-Shazly S, et al: Cytokine patterns in maternal blood after premature rupture of membranes. Obstet Gynecol 2001;98:122-126.

-63 Arababadi MK, Aminzadeh F, Hassanshahi $\mathrm{G}$, et al: Cytokines in preterm delivery. Lab Med 2011;43:27-30.

64 Raghupathy R, Al-Azemi M, Azizieh F: Intrauterine growth restriction: cytokine profiles of trophoblast antigen-stimulated maternal lymphocytes. Clin Dev Immunol 2012;2012: 734865.

65 Bowen JM, Chamley L, Keelan JA, et al: Cytokines of the placenta and extra-placental membranes: roles and regulation during pregnancy and parturition. Placenta 2002;23: 257-273.

66 Keelan JA, Mitchell MD: Placental cytokines and preeclampsia. Front Biosci 2007;12: 2706-2727.

67 Steinborn A, Von Gall C, Hildenbrand R, et al: Identification of placental cytokine-producing cells in term and preterm labor. Obstet Gynecol 1998;91:329-335.

68 Jokhi PP, King A, Loke YW: Cytokine production and cytokine receptor expression by cells of the human first trimester placentaluterine interface. Cytokine 1997;9:126-137.

69 Montes MJ, Tortosa CG, Borja C, et al: Constitutive secretion of interleukin- 6 by human decidual stromal cells in culture: regulatory effect of progesterone. Am J Reprod Immunol 1995;34:188-194.

70 Chaouat GA, Cayol V, Mairovitz, et al: Localization of Th2 cytokines IL-3, IL-4, IL-10 at the fetomaternal interface during human and murine pregnancy and lack of requirement for Fas/Fas ligand interaction for a successful allogeneic pregnancy. Am J Reprod Immunol 1999:42:1-13.

71 Dimitriadis E, White CA, Jones RL, et al: Cytokines, chemokines and growth factors in endometrium related to implantation. Hum Reprod Update 2005;11:613-630. 
72 Athanassiades A, Lala PK: Role of placenta growth factor (PIGF) in human extravillous trophoblast proliferation, migration and invasiveness. Placenta 1998;19:465-473.

73 Pang ZJ, Xing FQ: Comparative study on the expression of cytokine-receptor genes in normal and preeclamptic human placentas using DNA microarrays. J Perinat Med 2003;31: 153-162.

74 Benyo DF, Smarason A, Redman CW, et al: Expression of inflammatory cytokines in placentas from women with preeclampsia. J Clin Endocrinol Metab 2001;86:2505-2512.

-75 Hung TH, Charnock-Jones DS, Skepper JN, et al: Secretion of tumor necrosis factor-alpha from human placental tissues induced by hypoxia-reoxygenation causes endothelial cell activation in vitro: a potential mediator of the inflammatory response in preeclampsia. Am J Pathol 2004;164:1049-1061.

-76 Wang Y, Walsh SW: TNF alpha concentrations and mRNA expression are increased in preeclamptic pregnancies. J Reprod Immunol 1996;32:157-169.

-77 Conrad JP, Benyo DF: Placental cytokines and the pathogenesis of preeclampsia. Am J Reprod Immunol 1997;37:240-249.

-78 Tranquilli AL, Corradetti A, Giannubilo SR, et al: Placental cytokines in the pathogenesis of preeclampsia and HELLP syndrome. Curr Womens Health Rev 2008;4:280-285.

-79 Rinehart BK, Terrone DA, Lagoo-Deenadayalan S: Expression of the placental cytokines tumor necrosis factor alpha, interleukin-1beta and interleukin 10 is increased in preeclampsia. Am J Obstet Gynecol 1999;181: 915-920.

80 Ahmad S, Ahmad A: Elevated placental soluble vascular endothelial growth factor receptor-1 inhibits angiogenesis in preeclampsia. Circ Res 2004;95:884-891.

81 Gilbert JS, Ryan MJ, LaMarca BB, et al: Pathophysiology of hypertension during preeclampsia: linking placental ischemia with endothelial dysfunction. Am J Physiol Heart Circ Physiol 2008;294:H541-H550.

82 Caniggia I, Winter J, Lye SJ, et al: Oxygen and placental development during the first trimester: implications for the pathophysiology of preeclampsia. Placenta 2000;21(suppl A):S25-S30

83 Benyo DF, Miles TM, Conrad KP: Hypoxia stimulates cytokine production by villous explants from the human placenta. J Clin Endocrinol Metab 1997;82:1582-1588.

84 Utesheva Z, Kravtsova N, Dzoz L, et al: Cytokine investigations in organs and tissues of experimental animals under prenatal hypoxic conditions of varying sensitivity. Med Health Sci J 2011;6:136-140.

85 Huppertz B, Kingdom JC: Apoptosis in the trophoblast - role of apoptosis in placental morphogenesis. J Soc Gynecol Invest 2004;11: 353-362.

86 Huang X, Huang H, Dong M, et al: Serum and placental interleukin-18 are elevated in preeclampsia. J Reprod Immunol 2005;65:77-87.
87 Sakai M, Tsuda H, Tanebe K, et al: Interleukin-12 secretion by peripheral blood mononuclear cells is decreased in normal pregnant subjects and increased in preeclamptic patients. Am J Reprod Immunol 2002 47:91-97.

88 Sakai M, Shiozaki A, Sasaki Y, et al: The ratio of interleukin (IL)-18 to IL-12 secreted by peripheral blood mononuclear cells is increased in normal pregnant subjects and decreased in pre-eclamptic patients. J Reprod Immunol 2004;61:133-143.

89 Lockwood CJ, Yen CF, Basar M, et al: Preeclampsia-related inflammatory cytokines regulate interkeukin-6 expression in human decidual cells. Am J Pathol 2008;172:15711579.

90 Peng B, Koga K, Cardenas I, et al: Phagocytosis of apoptotic trophoblast cells by human endometrial endothelial cells induces proinflammatory cytokine production. Am J Reprod Immunol 2010;64:12-19.

91 Wilczinski JR, Tchorzeski H, Banasik M: Lymphocyte subset distribution and cytokine secretion in third trimester decidua in normal pregnancy and preeclampsia. Eur J Obstet Gynecol Reprod Biol 2003;109:8-15.

-92 Arriaga-Pizano L, Jimenez-Zamudio L, Vadillo-Ortega F: The predominant Th1 cytokine profile in maternal plasma of preeclamptic women is not reflected in the choriodecidual and fetal compartments. J Soc Gynecol Invest 2005;12:335-342.

93 Rein DT, Breidenbach M, Honscheid B, et al: Preeclamptic women are deficient of interleukin-10 as assessed by cytokine release of trophoblast cells in vitro. Cytokine 2003;23:119125.

94 Makris A, Xu B, Yu B, et al: Placental deficiency of interleukin-10 (IL-10) in preeclampia and its relationship to IL-10 promoter polymorphism. Placenta 2006;37:445-451.

95 Hennessy A, Pilmore HL, Simmons LA, et al: A deficiency of placental IL-10 in preeclampsia. J Immunol 1999;163:3491-3495.

96 Crocker IP, Cooper S, Ong SC, et al: Differences in apoptotic susceptibility of cytotrophoblasts and syncytiotrophoblasts in normal pregnancy to those complicated with preeclampsia and intrauterine growth restriction. Am J Pathol 2003;162:637-643.

-97 Ishihara N, Matsuo H, Murakoshi H, et al: Increased apoptosis in the syncytiotrophoblast in human term placentas complicated by either preeclampsia or intrauterine growth retardation. Am J Obstet Gynecol 2002;186: 158-166.

98 Difiderico E, Genbacev O, Fisher SJ: Preeclampsia is associated with widespread apoptosis of placental cytotrophoblasts within the uterine wall. Am J Pathol 1999;155: 293-301.

99 Ahn H, Park J, Gilman-Sachs A, et al: Immunologic characteristics of preeclampsia, a comprehensive review. Am J Reprod Immunol 2011;65:377-394.
100 Huang SJ, Zenclussen AC, Chen CP et al: The implication of aberrant GM-CSF expression in decidual cells in the pathogenesis of preeclampsia. Am J Pathol 2010;177: 2472-2482.

101 Vince GS, Starlkey PM, Austgulen R, et al: Interleukin-6, tumour necrosis factor and soluble tumour necrosis factor receptors in women with pre-eclampsia. Br J Obstet Gynaecol 1995;102:20-25.

102 Conrad KP, Miles TM, Benyo DF: Circulating levels of immunoreactive cytokines in women with preeclampsia. Am J Reprod Immunol 1998;40:102-111.

103 Kocygit Y, Atamer Y, Atamer A, et al: Changes in serum levels of leptin, cytokines and lipoprotein in pre-eclamptic and normotensive pregnant women. Gynecol Endocrinol 2004;19:267-273.

104 Serin IS, Ozelik B, Basbug M, et al: Predictive value of tumor necrosis factor alpha (TNFalpha) in preeclampsia. Eur J Obstet Reprod Biol 2002;100:143-145.

105 Velzing-Aarts FV, Muskiet FA, van der Dijs FP: High serum interleukin-8 levels in AfroCaribbean women with preeclampsia: relationships with tumor necrosis factor-alpha, duffy negative phenotype and von Willebrand factor. Am J Reprod Immunol 2002; 48:319-322.

106 Sacks GP, Studena K, Sargent IL, et al: Normal pregnancy and preeclampsia both produce inflammatory changes in peripheral blood leukocytes akin to those of sepsis. Am J Obstet Gynecol 1998;179:80-86.

107 Chen G, Wilson R, Wang SH, et al: Tumor necrosis factor- $\alpha$ (TNF- $\alpha$ ) gene polymorphism and expression in pre-eclampsia. Clin Exp Immunol 1996;104:154-159.

108 Kupferminc MJ, Peaceman AM, Aderka D, et al: Soluble tumor necrosis factor receptors in maternal plasma and second trimester amniotic fluid. Am J Obstet Gynecol 1995; 173:900-905.

109 Sibai B, Romero R, Klebanoff MA: Maternal plasma concentrations of the soluble tumor necrosis factor receptor 2 are increased prior to the diagnosis of preeclampsia. Am J Obstet Gynecol 2009;200:630.e1-e8.

110 Hamai Y, Fujii T, Yamashita T, et al: Evidence for an elevation in serum interleukin-2 and tumor necrosis factor-alpha levels before the clinical manifestations of preeclampsia. Am J Reprod Immunol 1997;38: 89-93.

111 Jonsson Y, Ruber M, Matthiesen L, et al: Cytokine mapping of sera from women with preeclampsia and normal pregnancies. J Reprod Immunol 2006;70:83-91.

-112 Freeman DJ, McManus FM, Brown EA Short- and long-term changes in plasma inflammatory markers associated with preeclampsia. Hypertension 2004;44:708-714.

-113 Nakabayashi M, Sakura M, Takeda Y, et al: Elevated IL-6 mid-trimester amniotic fluid is involved with the onset of preeclampsia. Am J Reprod Immunol 1998;39:329-334. 
114 Szarka A, Rigo J Jr, Lazar L, et al: Circulating cytokines, chemokines and adhesion molecules in normal pregnancy and preeclampsia determined by multiplex suspension array. BMC Immunol 2010;11:59-64.

115 Omu AE, Al-Qattan F, Diejomaoh ME: Differential levels of $\mathrm{T}$ helper cytokines in preeclampsia: pregnancy, labor and puerperium. Acta Obstet Gynecol Scand 1999;78: 675-680.

116 Saito S, Umekage Y, Sakamoto M, et al: Increased T-helper-1-type immunity and decreased T-helper-2-type immunity in patients with preeclampsia. Am J Reprod Immunol 1999;41:297-306.

-117 Darmochwal-Kolarz D, Rolinski J, Leszczynska-Goarzelak B: The expressions of intracellular cytokines in the lymphocytes of preeclamptic patients. Am J Reprod Immunol 2002;48:381-386.

-118 Darmochwal-Kolarz D, Leszczynska-Goarzelak B, Rolinski J: T helper-1 and T helper-2 cytokine imbalance in pregnant women with pre-eclampsia. Eur J Obstet Gynecol Reprod Biol 1999;86:165-170.

-119 Rein DT, Schondorf T, Gohring UJ: Cytokine expression in peripheral blood lymohocytes indicates a switch in T(helper) cells in patients with preeclampsia. J Reprod Immunol 2002;54:133-142.

120 Luppi P, Deloia JA: Monocytes of preeclamptic women spontaneously synthesize pro-inflammatory cytokines. Clin Immunol 2006;118:268-275.

121 Orange S, Horvath J, Hennessy A: Preeclampsia is associated with a reduced interleukin-10 production from peripheral blood mononuclear cells. Hypertens Pregnacy 2003;22:1-8.

122 Azizieh F, Raghupathy R, Makhseed M: Maternal cytokine production patterns in women with pre-eclampsia. Am J Reprod Immunol 2005;54:30-37.

123 Darmochwal-Kolarz D, Saito S, Rolinski J, et al: Activated T lymphocytes in pre-eclampsia. Am J Reprod Immunol 2007;58:39-45.

124 Saito S, Sakai M, Sasaki Y, et al: Quantitative analysis of peripheral blood Th0, Th1, Th2 and the Th1:Th2 cell ratio during normal human pregnancy and preeclampsia. Clin Exp Immunol 1999;117:550-555.

-125 Zenclussen AC: A novel mouse model for preeclampsia by transferring activated th 1 cells into normal pregnant mice. Methods Mol Med 2006;122:401-412.

126 Germain SJ, Sacks GP, Sooranna SR, et al: Systemic inflammatory priming in normal pregnancy and preeclampsia: the role of circulating syncytiotrophoblast microparticles. J Immunol 2007;178:5949-5956.

-127 Sasaki Y, Darmochwal-Kolarz D, Suzuki D, et al: Proportion of peripheral blood and decidual $\mathrm{CD} 4+\mathrm{CD} 25$ (bright) regulatory $\mathrm{T}$ cells in pre-eclampsia. Clin Exp Immunol 2007;149:139-145.
128 Santner-Nanan B, Peek MJ, Khanam R, et al: Systemic increase in the ratio between Foxp $3^{+}$and IL-17-producing CD $4^{+} \mathrm{T}$ cells in healthy pregnancy but not in preeclampsia. J Immunol 2009; 183:7023-7030.

129 Paeschke S, Chen F, Horn N, et al: Pre-eclampsia is not associated with changes in the levels of regulatory $\mathrm{T}$ cells in peripheral blood. Am J Reprod Immunol 2005;54:384389.

130 Sibai BM: Initiators of severe pre-eclampsia: Semin Perinatol 2009;33:196-205.

131 Redman CW, Sacks GP, Sargent IL: Preeclampsia: an excessive maternal response to pregnancy, Am J Obstet Gynecol 1999;180: 499-506.

132 Chen LM, Liu B, Zhao HP, et al: IL-6, TNFalpha and TGFbeta promote nonapoptotic trophoblast deportation and subsequently causes endothelial cell activation. Placenta 2010;31:75-80.

133 Kharfi A, Giguere Y, Sapin V, et al: Trophoblastic remodeling in normal and preeclamptic pregnancies: implication of cytokines. Clin Biochem 2003;36:323-331.

134 Kofler S, Nickel T, Weis M: Role of cytokines in cardiovascular diseases: a focus on endothelial responses to inflammation. Clin Sci (Lond) 2005;108:205-213.

135 Naldini A, Carraro F: Role of inflammatory mediators in angiogenesis. Curr Drug Targets Inflamm Allergy 2005;4:3-8.

136 Kaplansjuki G, Fabrigoule M, Boulay V: Thrombin induces endothelial type II activation in vitro: IL-1 and TNF-alpha-independent IL-8 secretion and E-selectin expression, -alpha-independent IL-8 secretion and E-selectin expression. J Immunol 1997; 158:5435-5441.

137 Madazli R, Aydin S, Uludag S, et al: Maternal plasma levels of cytokines in normal and preeclamptic pregnancies and their relationship with diastolic blood pressure and fibronectin levels. Acta Obstet Gynecol Scand 2003;82:797-802.

138 Granger JP, Alexander BT, Llinas T, et al: Pathophysiology of preeclampsia linking placental ischemia/hypoxia with microvascular dysfunction. Microcirculation 2002;9: 147-160.

139 Granger JP: Inflammatory cytokines, vascular function and hypertension. Am J Physiol Regul Integr Comp Physiol 2004;286:R989R990.

140 Claman JY, Rapaport V, Repinski C, et al: Analysis of superoxide generation, cytokine production, and adhesion molecular production in normal pregnant and preeclamptic patients. J Soc Gynecol Investig 1997; 4:S192A.

141 Zenclussen AC, Lim E, Knoeller S, et al: Heme oxygenases in pregnancy II: $\mathrm{HO}-2$ is downregulated in human pathologic pregnancies. Am J Reprod Immunol 2003;50: 66-76.
142 Wong RJ, Zhao H, Stevenson DK: A deficiency in haem oxygenase-1 induces foetal growth restriction by placental vasculature defects. Acta Paediatr 2012;101:827-834.

143 Zhao H, Wong RJ, Kalish FS, et al: Effect of heme oxygenase-1 deficiency on placental development. Placenta 2009;30:861-868.

144 Hayashi M, Inoue T, Hoshimoto K, et al: Characterization of five marker levels of the hemostatic system and endothelial status in normotensive pregnancy and preeclampsia. Eur J Haematol 2002;69:297-302.

145 Sibai BM: Initiators of severe pre-eclampsia. Semin Perinatol 2009;33:196-205.

146 George EM, Granger JP: Endothelin: key mediator of hypertension in preeclampsia. Am J Hypertens 2011;24:964-969.

147 Leibowitz A, Schiffrin EL: Immune mechanisms in hypertension. Curr Hypertens Rep 2011;13:465-472.

148 Tinsley JH, Chiasson VL, South S, et al: Immunosuppression improves blood pressure and endothelial function in a rat model of pregnancy-induced hypertension. Am J Hypertens 2009;22:1107-1114.

149 Saito S, Nakashima A, Shima T, et al: Th1, Th2, Th17 and regulatory T-cell paradigm in pregnancy. Am J Reprod Immunol 2010;63: 601-610.

150 Taslinipar A, Yaman H, Yilmaz MI, et al: Relationship between inflammation, endothelial dysfunction and proteinuria in patients with diabetic nephropathy. Scand J Clin Lab Invest 2011;71:606-612.

151 Orange S, Rasko JE, Thomson JF, et al: Interleukin-10 regulates arterial pressure in early primate pregnancy. Cytokine 2009;29:176185.

152 Chatterjee P, Chiasson VL, Kopriva SE, et al: Interleukin-10 deficiency exacerbates Tolllike receptor 3-induced preeclampsia-like symptoms in mice. Hypertension 2011;58: 489-496.

153 White CA, Johansson M, Roberts CT, et al: Effect of interleukin-10 null mutation on maternal immune response and reproductive outcome in mice. Biol Reprod 2004;70: 123-131.

154 Keiser SD, Veillon EW, Parrish MR, et al: Effects of 17-hydroxyprogesterone on tumor necrosis factor-alpha-induced hypertension during pregnancy. Am J Hypertens 2009;22:1120-1125.

155 Raghupathy R, Al Mutawa E, Makhseed M, et al: Modulation of cytokine production by dydrogesterone in lymphocytes from women with recurrent miscarriage. Br J Obstet Gynecol 2005;112:1096-1101.

156 Raghupathy R, Al Mutawa E, Makhseed M, et al: Redirection of cytokine production by lymphocytes from women with pre-term delivery by dydrogesterone. Am J Reprod Immunol 2007;58:31-38.

157 Raghupathy R, Kalinka J: Cytokine imbalance in pregnancy complications and its modulation. Front Biosci 2008;13:985-994. 